\title{
Parenting Skills Determinant in Preventing Adolescents' Sexual Health Risk Behavior
}

\author{
Rosnah Sutan, Aimi Nazri Mahat \\ Department of Community Health, Universiti Kebangsaan Malaysia Medical Centre, Kuala Lumpur, Malaysia \\ Email: rosnah_sutan@yahoo.com
}

How to cite this paper: Sutan, R. and Mahat, A.N. (2017) Parenting Skills Determinant in Preventing Adolescents' Sexual Health Risk Behavior. Open Journal of Preventive Medicine, 7, 1-13. http://dx.doi.org/10.4236/ojpm.2017.71001

Received: December 13, 2016

Accepted: January 3, 2017

Published: January 6, 2017

Copyright ( 92017 by authors and Scientific Research Publishing Inc. This work is licensed under the Creative Commons Attribution International License (CC BY 4.0).

http://creativecommons.org/licenses/by/4.0/ (c) (i) Open Access

\begin{abstract}
Parenting skill is one of the crucial needs that parents must have in caring adolescents' sexual health risk behavior. Present study aims to determine predictors of parenting skills in preventing adolescents' sexual health risk behavior. A cross sectional study was conducted among adolescents' parents who attended government health clinics in a semi-urban district, West Malaysia. Data were collected by systematic random sampling using validated questionnaire from eight government health clinics based on routine daily out-patient services. There were 386 respondents participated with $98.9 \%$ of response rate. Parental skill is categorized as appropriate or inappropriate based on Trans-Theoretical Model (TTM) staging. Eighteen independent variables were used: parental socioeconomic status, adolescent characteristic, parenting style, parent-adolescent communication, parental stress, perception on adolescent sexual risk, comfortable in discussing sexual issues, knowledge in sexual reproductive health (SRH) and knowledge in HIV/AIDS. Assessment of parenting skills using the TTM stage showed 139 respondents (36\%) had inappropriate parenting skills, in which they were in pre contemplation, contemplation or preparedness stages, while 247 respondents (64\%) showed appropriate parenting skills when they were in action and maintenance stages of TTM. Older parent, late adolescent, low parental education level, extended family living arrangement, comfortable in discussing sexual issues, good parent-adolescent communication and higher knowledge in HIV/AIDS were found significant in bivariate analysis. Multivariate logistic regression analysis identified older parent $(\mathrm{AOR}=1.927,95 \% \mathrm{CI}=1.889-1.966, \mathrm{p}<0.001)$, lower parental education $(\mathrm{AOR}=2.394,95 \% \mathrm{CI}=1.348-4.254, \mathrm{p}=0.003)$, comfortable in discussing sexual issues $(\mathrm{AOR}=3.810,95 \% \mathrm{CI}=1.622-8.948, \mathrm{p}=$ 0.002), good parent-adolescent communication $(\mathrm{AOR}=4.741,95 \% \mathrm{CI}=2.478$ - 9.071, $\mathrm{p} \leq 0.001)$ and having higher knowledge on HIV/AIDS (AOR = 2.804, $95 \% \mathrm{CI}=1.528-5.147, \mathrm{p}=0.001)$ as significant predictors for appropriate parenting skills in preventing adolescent sexual health risk behavior. In conclusion, more than one third of parents were still not ready in preventing ado-
\end{abstract}


lescent sexual risk behavior. Targeting the young parents and those having difficulty in communicating sexual issues with theirs adolescents should be emphasized in early intervention program for parents. Self-assessment using TTM stage questionnaire will help parents to identify their parenting skills in preventing adolescent sexual health risk behavior.

\section{Keywords}

Trans-Theoretical Model Staging, Parenting Skills, Adolescent Sexual Risk Behavior

\section{Introduction}

Parenting skill is an important element that affects parents in educating their children and ensuring excellence of all aspects in their life. It is one of the crucial needs that parents must have in caring adolescent sexual health risk behavior. The best parenting skill approached is not naturally born but must be learned and practiced by every parent to ensure the health and safety of their children. The positive relationship between appropriate parenting skills and good adolescents' behavior has been proven by previous research in terms of academic achievement, problem solving skills, risky behavior, mental health, self-esteem and depression [1] [2] [3] [4]. Improving the sexual and reproductive health development of adolescent is a global priority that needs a systematic and targeted approach in facing the challenges. However, efforts to promote this healthy sexual development were commonly targeting adolescents through school or community-based programs but less effort has been focused on enhancing the role of parents in raising sexually healthy adolescents. In fact, parents do have a strong influence on their adolescents' sexual and reproductive health and risk behaviors.

Therefore, parenting skill is very important to focus on ensuring the excellence of their adolescents. They should be made aware of the complex roles and accountability in parenting skills. In fact, parenting skills must be equipped with relevant knowledge and practical preparations to deal with health-related issues and foster self-esteem practice in prevention of adolescents' sexual health risk behavior. Governments need to identify those who do not practice appropriate parenting skills and provide support in achieving the goal of establishing a future generation of excellence, glory and distinction. Keep in mind, parent do have a strong influence on the behavior of risky adolescent sexual and reproductive health.

Home environment as one of the many layers of environments is an important initial focal point for adolescents to develop a good sexual and reproductive health behavior. Encouraging parental role through positive parent-adolescent relationship in term of connectedness, communication and monitoring is based on the assumption that such relationships between parents and adolescent can 
lead to positive attitudes to life and lower levels of risk-taking behavior, especially in sexual and reproductive health. By providing avenues for this parental role, home is expected to serve as a stabilizing factor in the lives of adolescent. Other person in the immediate environment, relationships and agents such as peers, schools and community members as well as the national socio-political system constitute the other layers involved in the transmission and acquisition of knowledge and experiences, networking and support systems for adolescents' sexual and reproductive health [5] [6].

A promising approach of Trans Theoretical Model (TTM) of behavior change developed by Prochaska \& DiClemente [7] in assessing health behaviors of people have been used across in many studies for at least forty-eight behaviors assessment. The TTM emerged from a comparative analysis of leading theories of psychotherapy and behavior change in an effort to integrate a field that had fragmented into more than 300 theories of psychotherapy [7]. It uses stages of change to integrate processes and principles of change across major theories of intervention. Many researches have provided strong support for the reliability and validity of the TTM core constructs, including stages of change [8]. The stages of change are the central organizing construct of the TTM, representing the temporal and readiness dimension.

As people change behavior, they progress through a series of stages involving a linear movement but normally, the change is usually cyclical in pattern. From initial studies using the TTM with its stage model on smoking, it has rapidly expanded to include investigations and applications to a broad range of health and mental health behaviors, including alcohol and substance abuse, anxiety and panic disorders, bullying, delinquency, depression, eating disorders and obesity, high-fat diets, HIV/AIDS prevention, mammography and other cancer screening. Therefore, assessment on parenting skills in preventing adolescent sexual risk behavior by using the TTM staging will give a new paradigm in health service research. Present study aims to assess parenting skills using Trans-Theoretical Model (TTM) staging and to determine its predictors in preventing adolescent sexual health risk behavior.

\section{Materials and Methods}

A cross sectional study was conducted among adolescents' parents from a semi urban district. Kuala Selangor district is one of the semi urban district outskirt the Greater Kuala Lumpur. There are eight Governmental health clinics under the administration of Kuala Selangor District Health Office and all of them were chosen for sample population. The target population was the parents or caretakers who attending the governmental health clinics in Kuala Selangor District, Selangor. The list of names for sample frame selection was retrieved from clinic services registration. The selection criteria of the participant were: parents or caretakers of adolescent of age between 13 and 19 year old, who came to the chosen Government clinics and either father or mother were included in this study. The selection technique for participants was based on random sampling 
from the list of sampling frame. The participants answered the questionnaires given to them personally after informed consent taken. To determine the sample size, a power analysis for dichotomous variables was conducted in Epi Info 7 Stat Calc [9]. The calculated sample size required 390 respondents. Ethical approval was obtained from Universiti Kebangsaan Malaysia Research Ethics Committee (UKMREC) and was conducted in accordance to Good Clinical Practice (GCP) requirements.

The study tool used was the self-administered questionnaire. All sections in the questionnaire were undergoing validity and reliability beforehand. The questionnaire was developed for this study by adopting and modifying tools from number of existing studies related to parenting skills in preventing adolescents' sexual health risk behavior. The questionnaire consists of five sections namely general information, Parenting Style Questionnaire, Parent-Teen communication about sexual health topics, knowledge about sexual and reproductive health and TTM assessment of parenting skills.

Part A is on general information section which covers the socio-demographic data of the respondents and their adolescents. These include age, gender, race, education level, marital status, occupation, income, employment and family type. The second part is a questionnaire about general information on adolescents, perceived stress of raising children, the perception of sexual risk behavior in adolescents and parent-adolescent communication on sexual health topics.

Part B section measures the parenting styles practiced by the respondents in bearing their adolescents. This questionnaire is taken from Parenting Styles and Dimensions Questionnaire (SDQ) [10]. It consists of three types of parenting style which are authoritarian, authoritative and permissive. The questionnaire was modified based on the context of society and culture of Malaysia. SDQ consists of 32 items to identify the characteristics of parenting styles adopted by parents as daily practice.

Part C contains a questionnaire about parent-adolescent communication on sexual and reproductive health topics. The questionnaire was adapted from "Parent-Teen Communication about Sexual Risk" developed by Hutchinson K.K. [11]. It consists of eight items or topics in which parents should talk to their children in preventing risky sexual behavior. Eight titles were listed: contraception, sexually transmitted infections, HIV/AIDS, how to avoid getting sexually transmitted infections and AIDS, roles of condoms specifically, and ways to resist sexual pressure and peer-pressure from male or female friends.

Part D of the questionnaire was related to the respondents' knowledge on sexual and reproductive health, sexual transmitted disease and HIV/AIDS. The questions are divided into two main categories: knowledge about sexual and reproductive health, while the second part is the questions about sexually transmitted infections and HIV/AIDS. All of these questions are adapted from Illustrative Questionnaire for interview-Surveys with Young People [12].

The last part of the questionnaire (Part E) is the TTM assessment of parenting skills in prevention of adolescent sexual health risk behavior. This questionnaire 
is undergoing the verification process (face, content, construct) and pre-testing prior to use in the field. There are a total of 19 items with four main domains: parental involvement, rewards, monitoring and discipline or punishment use in parenting. The parenting skills level is divided into five stages, namely no desire (pre-contemplation), want to do (contemplation), ready to do (preparedness), have done (action) and always do (maintenance). Likert scale response option was used for each 19 items to determine five TTM stages. Scores are given for each alternative answers for no desire (0 mark), want to do (1 mark), ready to do ( 2 marks), have done (3 marks) and always do (4 marks). Higher scores indicate appropriateness of preventing adolescents' sexual health risk behavior. The parenting skill is categorized into 2 categories: appropriate parenting skills if score is 39 and above ( $\geq 39$ marks) and not appropriate if score below 39 ( $<39$ marks). Assessment of parental skill using TTM staging was later regrouped into appropriate level (action and maintenance stage) or inappropriate level of parenting skill (pre contemplation, contemplation and preparedness stage). Data collection was done between May-June 2016 at Kuala Selangor district. The statistical package SPSS version 22 was used for data analysis. The prevalence of appropriate parenting skill in preventing adolescents' sexual health risk behavior and its predictor is measured by using the descriptive analysis. To measure the association between appropriate parenting skill and the factors influencing it, we used the chi square test for categorical data. The $t$ test was used for comparison of continuous variables with normal distribution. Multivariable logistic regression analysis was used to predict factors associated with appropriate parenting skill in preventing adolescent sexual health risk behavior. A predictor model for appropriate parenting skill is produced at the end of this analysis. Significant associations were taken at $p$ values of less than 0.05 and $95 \%$ confidence interval.

\section{Results and Discussion}

In total, there were 386 respondents participated (98.9\%). Majority of the participants were male (52.1\%), Malay ethnic group (56.2\%), Muslims (57.8\%), married (96.1\%), stay-in nucleus family type (72.9\%), education level up to secondary school (79.5\%) and had higher family income above the state average income (67.1\%). The participants have varies occupational types representing to general population of a semi urban district. Assessment of parenting skills using the TTM stages showed 139 respondents (36\%) had inappropriate parenting skills (pre contemplation, contemplation or preparedness stages). While, 247 respondents (64\%) showed appropriate parenting skills in which the participants were at the action and maintenance stages. It means that the prevalence of appropriate parenting skill in preventing adolescent sexual health risk behavior in the population was only $64 \%$.

For the TTM assessment questionnaire on parenting skills which has been validated, showed that it can be used to assess parenting skills in preventing adolescent sexual health risk behavior. The questionnaire used in this study was able to obtain the pattern of parenting skills and give ideas on how parents used in 
parenting their adolescents. Based on the distribution of respondent's answers in the TTM assessment of parenting skills, it was found that respondents practice appropriate parenting skills at the level of action (have done) and maintenance (always do) most of the items belong to the monitoring component followed by items parental involvement, rewards and lastly punishment. The items on asking "You make sure your adolescent ask permission every time hel she go for activities", "You tend to know every activities of your adolescent in term of 1) time, 2) where 3) person involved 4) type of activities" and "You don't let your adolescent go out with friends you don't know" showed a response rate of more than $60 \%$ of appropriate parenting skills and are belong to the category of monitoring within the scope of parenting skills. Items that showed the least appropriate parenting skill is an item that asks, "The punishment you give to your adolescent is not influence by your mood status", which scored only 3.7\%, followed by the item "You give punishment to your adolescent if hel she did something wrong related to risky sexual behavior" which scored $12.2 \%$. Both of these items were in the category of penalties within the scope of parenting skills.

This means that most parents adopt high level of monitoring on their adolescents in preventing risky sexual behavior of adolescents. The parents also showed good involvement and relationships with their adolescents. Both of these factors have been demonstrated in previous studies that play an important role in ensuring good behavior for adolescents that will make them excel in their respective fields. However, parents have seen to have inappropriate parenting skill within the dimensions of punishment and rewards. This may be due to cultural factors and upbringing of people in this country who are less practicing giving gifts to any success performed by the child and rarely give severe penalties if the adolescent made any mistake. Nonetheless, the law is discouraging the action and new generation seem to be reluctant for that kind of parenting.

The majority of the respondents were male, aged between 41 - 59 years, Malay, Muslim, married, live in nuclear families and have low education levels. Almost one-third of respondents work in the private sector, followed by business, government employees, housewives, agriculture and a few in the professional field. Most of the respondents were individuals who have high incomes that exceed RM3000 a month. This pattern was almost similar to surveys done in Selangor and also at national level [13]. Therefore, the results of this study can give an idea of the actual data to the Selangor state in general. Based on the bivariate analysis of these socio-demographic factors, it was proved that parental age, adolescents' age, family type and level of education is a significant factor in influencing appropriate parenting skills in the prevention of adolescents' sexual health risk behavior. Table 1 and Table 2 showed the association between parenting skill and its associated factors.

Multivariate logistic regression analysis identified older parent $(\mathrm{AOR}=1.927$, $95 \% \mathrm{CI}=1.889-1.966, \mathrm{p}<0.001)$, lower parental education $(\mathrm{AOR}=2.394,95 \%$ $\mathrm{CI}=1.348-4.254, \mathrm{p}=0.003)$, comfortable in discussing sexual issues $(\mathrm{AOR}=$ $3.810,95 \% \mathrm{CI}=1.622-8.948, \mathrm{p}=0.002)$, good parent-adolescent communica- 
tion $(\mathrm{AOR}=4.741,95 \% \mathrm{CI}=2.478-9.071, \mathrm{p} \leq 0.001)$ and having higher knowledge on HIV/AIDS (AOR $=2.804,95 \% \mathrm{CI}=1.528-5.147, \mathrm{p}=0.001$ ) as significant predictors for appropriate parenting skills in preventing adolescent sexual health risk behavior among parents. Table 3 showed the predictors model from the multivariate analysis using multiple logistic regression.

Parental age is among the most important factors in influencing the pattern of parenting skills. Analysis of this study has shown that older parents practice appropriate parenting skill in preventing risky sexual behavior of adolescents than

Table 1. Relationship between parenting skill and socio-demographic factors.

\begin{tabular}{|c|c|c|c|c|}
\hline \multirow[b]{2}{*}{ Variables } & \multicolumn{2}{|c|}{ Parenting skills } & \multirow[b]{2}{*}{$\mathrm{X}^{2}$} & \multirow[b]{2}{*}{$\mathrm{p}$ value } \\
\hline & $\begin{array}{c}\text { Appropriate } \\
\text { n (\%) }\end{array}$ & $\begin{array}{c}\text { Inappropriate } \\
\mathrm{n}(\%)\end{array}$ & & \\
\hline \multicolumn{5}{|l|}{ Gender } \\
\hline $\begin{array}{c}\text { Male } \\
\text { Female }\end{array}$ & $\begin{array}{l}130(64.7) \\
117(63.2)\end{array}$ & $\begin{array}{l}71(35.3) \\
68(36.8)\end{array}$ & 0.086 & 0.769 \\
\hline \multicolumn{5}{|l|}{ Race } \\
\hline Non Malay & $137(63.1)$ & $\begin{array}{l}80(36.9) \\
59(34.9)\end{array}$ & 0.158 & 0.691 \\
\hline \multicolumn{5}{|l|}{ Religion } \\
\hline Non Muslim & $139(62.3)$ & $84(37.7)$ & 0.630 & 0.427 \\
\hline \multicolumn{5}{|l|}{ Marital status } \\
\hline Single/Divorce & $237(63.9)$ & $\begin{array}{c}5(33.3) \\
134(36.1)\end{array}$ & 0.049 & 0.826 \\
\hline \multicolumn{5}{|l|}{ Type of family } \\
\hline $\begin{array}{l}\text { Extended } \\
\text { Nucleus }\end{array}$ & $169(60.1)$ & $27(25.7)$ & 6.636 & $0.010^{*}$ \\
\hline \multicolumn{5}{|l|}{ Education level } \\
\hline $\begin{array}{l}\text { Low } \\
\text { High }\end{array}$ & $209(68.5)$ & $96(31.5)$ & 12.972 & $<0.001^{\star}$ \\
\hline \multicolumn{5}{|l|}{ Family income } \\
\hline High & $173(66.8)$ & $\begin{array}{l}53(41.7) \\
86(33.2)\end{array}$ & 2.689 & 0.101 \\
\hline \multicolumn{5}{|l|}{ Occupation } \\
\hline Professional & $41(57.7)$ & $30(42.3)$ & \multirow{6}{*}{19.682} & \multirow{6}{*}{$0.001^{*}$} \\
\hline Business & $20(67.7)$ & $10(33.3)$ & & \\
\hline Agriculture & $44(62.0)$ & $27(38.0)$ & & \\
\hline Government & $41(57.7)$ & $30(42.3)$ & & \\
\hline Private & $20(67.7)$ & $10(33.3)$ & & \\
\hline Housewife & $44(62.0)$ & $27(38.0)$ & & \\
\hline
\end{tabular}


Table 2. Relationship between parenting skill and other factors.

\begin{tabular}{|c|c|c|c|c|}
\hline \multirow[b]{2}{*}{ Variables } & \multicolumn{2}{|c|}{ Parenting skills } & \multirow[b]{2}{*}{$\mathrm{X}^{2}$} & \multirow[b]{2}{*}{$\mathrm{p}$ value } \\
\hline & $\begin{array}{c}\text { Appropriate } \\
\mathrm{n}(\%)\end{array}$ & $\begin{array}{c}\text { Inappropriate } \\
\mathrm{n}(\%)\end{array}$ & & \\
\hline \multicolumn{5}{|l|}{ Parenting style } \\
\hline Authoritative & $204(63.9)$ & $115(36.1)$ & \multirow{3}{*}{0.988} & \multirow{3}{*}{0.610} \\
\hline Authoritarian & $8(53.3)$ & $7(46.7)$ & & \\
\hline Permissive & $35(67.3)$ & $17(32.7)$ & & \\
\hline \multicolumn{5}{|c|}{$\begin{array}{l}\text { Perception on adolescent } \\
\text { having sexual risk }\end{array}$} \\
\hline $\begin{array}{l}\text { Yes } \\
\text { No }\end{array}$ & $125(65.4)$ & $\begin{array}{l}73(37.4) \\
66(34.6)\end{array}$ & 0.348 & 0.556 \\
\hline \multicolumn{5}{|c|}{$\begin{array}{l}\text { Perception on stress raising } \\
\text { adolescent }\end{array}$} \\
\hline $\begin{array}{l}\text { Yes } \\
\text { No }\end{array}$ & $\begin{array}{l}83(61.5) \\
164(65.3)\end{array}$ & $\begin{array}{l}52(38.5) \\
87(34.7)\end{array}$ & 0.567 & 0.452 \\
\hline \multicolumn{5}{|c|}{ Comfort in talking sexual issues } \\
\hline $\begin{array}{l}\text { Yes } \\
\text { No }\end{array}$ & $238(67.2)$ & $\begin{array}{l}116(32.8) \\
23(71.9)\end{array}$ & 19.477 & $<0.001^{\star}$ \\
\hline \multicolumn{5}{|c|}{$\begin{array}{l}\text { Parent adolescent communication } \\
\text { on sexual topics }\end{array}$} \\
\hline $\begin{array}{c}\text { Effective } \\
\text { Not effective }\end{array}$ & $\begin{array}{l}100(87.0) \\
147(54.2)\end{array}$ & $\begin{array}{c}15(13.0) \\
124(45.8)\end{array}$ & 37.496 & $<0.001^{\star}$ \\
\hline \multicolumn{5}{|c|}{ Knowledge on SRH } \\
\hline Low & $\begin{array}{l}193(64.5) \\
54(62.1)\end{array}$ & $\begin{array}{l}106(35.5) \\
33(37.9)\end{array}$ & 0.180 & 0.672 \\
\hline \multicolumn{5}{|c|}{ Knowledge on STD, HIV/AIDS } \\
\hline High & $216(67.7)$ & $103(32.3)$ & 11.049 & $0.001^{*}$ \\
\hline
\end{tabular}

Table 3. Predictors model of appropriate parenting skill in preventing adolescents' sexual health risk behavior in Selangor.

\begin{tabular}{|c|c|c|c|c|c|c|c|}
\hline & \multirow{2}{*}{$(\beta)$} & \multirow{2}{*}{ SE } & \multirow{2}{*}{ Wald } & \multirow{2}{*}{$\mathrm{p}$ value } & \multirow{2}{*}{$\begin{array}{c}\text { Adjusted Odds } \\
\text { Ratio }(\exp \beta)\end{array}$} & \multicolumn{2}{|c|}{ Confidence interval } \\
\hline & & & & & & Lower & Upper \\
\hline Constant & 0.599 & & & & & & \\
\hline Parental age & 0.076 & 0.021 & 13.085 & $<0.001$ & 1.927 & 1.889 & 1.966 \\
\hline Education level & 0.873 & 0.293 & 8.868 & 0.003 & 2.394 & 1.348 & 4.254 \\
\hline Feel comfort talking sexual issue & 1.338 & 0.436 & 9.428 & 0.002 & 3.810 & 1.622 & 8.948 \\
\hline Parent adolescent communication & 1.556 & 0.331 & 22.098 & $<0.001$ & 4.741 & 2.478 & 9.071 \\
\hline Knowledge on STD, HIV/AIDS & 1.031 & 0.310 & 11.071 & 0.001 & 2.804 & 1.528 & 5.147 \\
\hline
\end{tabular}

Method backward stepwise; R2 (Nagelkerke R square $=0.304$ ); Hosmer \& Lemeshow test p value $=0.448$; Receiver Operating Characteristic $($ ROC) curve $=$ 0.718 ; No outlier. 
younger parents. The age distribution also showed that all old parents ( $\geq 60$ years old) have appropriate parenting skills compared to $71.4 \%$ of parents aged 41 - 60 years and only $46.3 \%$ of parents aged $\leq 40$ years old. This significant disparity reflects the actual pattern of parenting skills is varying according to age and their generation. Among the factors that may contribute to the difference between the generation patterns of parenting skills was noted that old parents were more conservative in guiding their adolescents while younger parents were seen more permissive in monitoring the activities of their adolescents. This condition may be caused by lifestyle, environmental factors and changes in socio-economic conditions prevailing from time to time, or better known as the "generation gap" that exists in the context of the family institution [14] [15].

Low parental educational level was found lower in practicing appropriate parenting skills compared to parents with higher education levels. The educational level of the mother was noted in earlier study as the power that important in educating and raising children [16]. Highly educated parents often see children as bilateral relations, reciprocal frequent involvement in children's learning and practicing positive and open communication [16]. These help in improving children's moral development and reduce risky sexual behavior. Although the results of this study were contrary to the findings of previous studies [16] [17] [18], this can be explained when taking context of the education system available and cultural communities of the semi urban district. In actual fact, the majority of parents with higher education levels are generally attended boarding school and entering the university during their adolescence age. This causes them to be in a system in which their lives have been arranged and organized with their peers at school and pre-university. Lack of exposure to the outside world and guidance directly from parents can lead to lack of experience and knowledge in guiding their own adolescents later. In addition, well-educated parents are also involved in the work that requires high commitment of time and great challenges. These resulted in spending less time with children and fail to practice appropriate parenting skills in preventing adolescent sexual health risk behavior.

Among other characteristics identified significantly associated with appropriate parenting skills in this study are feeling comfortable in discussing sexual issues and good parent-adolescent communication on sexual health topics. In this study, majority of respondents felt comfortable talking about sexual health with their teenagers but the level of parent-adolescent communication on sexual health topics showed low scores. The score parent-adolescent communication showed that only $29.8 \%$ of respondents have effective communication. Sexual health topics such as contraception or pregnancy prevention and sexually transmitted diseases, using condoms specifically were found to be the least topic was discussed between parent and adolescent. However, analysis has showed that both factors actually have a strong relationship with appropriate parenting skills that must be practice by parents.

According Guilamo-Ramos V \& Souris A. [19], adolescents who have parents that are open-minded, responsive, comfortable and confident in talking about 
sex and sex related issues were less involved in risky sexual behavior. This shows that the quality and comfort in the parent-adolescent communication affect messages received by adolescents about sex. Furthermore, a recent meta-analysis study by Laura et al. [20] showed a significant relationship between parent adolescent communication and decreased adolescent sexual health risk behavior. A study by Martino SC. [21] stated that adolescents who often communicate about sexual and reproductive health topics with their parents are more likely to have an open relationship and closer to their parents. Teenagers, who are more likely to talk with their parents about sexual problems, will show reducing risky behavior of sexual reproductive health.

Effective parent adolescent communication on sexual health topic is also associated with increased psychosocial attributes such as increased sexual health knowledge, good interpersonal communication in denial of sexual relations and increased self-esteem among adolescents [22] [23]. Furthermore, effective communication between parents and adolescents is also identified as a protective factor for preventing risky sexual behavior, especially in the context of avoiding sexual relationships [24] [25]. If avoiding intercourse, this means that adolescent will also be able to reduce the risk of sexually transmitted diseases, unwanted pregnancies and abortions as a result of the sexual relationship. All of these highlighted the importance of the Parent's ability and confidence in communicating sexual health and practicing appropriate parenting skills helps in preventing adolescents from sexual health risk behaviors.

In this study, parental knowledge on sexual transmitted diseases and HIV/ AIDS was also found significant determinant of appropriate parenting skills in preventing adolescent sexual health risk behavior. Parents are the primary source and the most approachable person in the family institution. Adolescents often make their parents as a role model and source of information for sexual and reproductive health [26]. Therefore, parents who have high knowledge on sexual health will help their adolescent towards a healthy sexual life. In addition, knowledge in the field of sexual health will also allow parents to understand the risks faced by adolescent if they involved in risky sexual behavior. Parents should play important role in preventing risky behavior by advising and guiding their adolescents toward healthy sexual life. This has been demonstrated through a systematic study review by Burrus et al. [27] which prove the intervention of health education to parents that involve collaboration between health personnel and parents can reduce sexual behavior among adolescent, improve protective attitude and ensure healthy sexual life among adolescent through enhancement of parenting skills.

The present study has its limitation in determine the overall parenting skills. The questionnaire was constructed only for sexual reproductive health component on adolescent age group. The questionnaire was not adjusted according to different socio-cultural perspective practice in Malaysia. An assumption that the minimum expected to be inculcate as parenting skills should be available and measurable. Because of this, it can be used for future intervention study in eva- 
luating its impact on parenting skills.

\section{Conclusions and Recommendations}

In conclusion, more than one third of parents were still not ready in preventing adolescent sexual risk behavior which mean that they are still having inappropriate parenting skill. TTM assessment can be done among parents in identifying the level of parenting skills. Self-assessment using this questionnaire helps parents to identify their parenting skills in preventing adolescent sexual health risk behavior. Other than that, this TTM assessment of parenting skills questionnaire that have been produced can be also used in future study to examine different population and get more data on patterns of parenting skills in preventing adolescent sexual health risk behavior as national profile and follow its trend by different generation. This will help parents to be aware on their parenting skills and take proactive steps to improve their parenting skills in preventing adolescent sexual health risk behavior.

In this study, the parental age is significant determinant of appropriate parenting skills. Young parents who have weakness in parenting skill need to be targeted in future Planned Parenthood programs. The elder parent who is successful in educating and guiding their adolescent to excel can also be invited to share their views and experience of parenting skills in preventing adolescents' sexual health risk behavior. For education level, it was found that parent with high education level are at a greater risk for practicing inappropriate parenting skills. Therefore, it is suggested that parenting programs need to be organized in the universities to provide early exposure to this group and introduced the concept of good parenting. In addition, parenting skills program should be promoted and targeted more to those with higher education in creating awareness and imparting knowledge to their best parenting skills. It was also found that the element of parent adolescent communication on sexual health topic and feeling comfortable during talking about sexual health with adolescent were the determinant of appropriate parenting skill. Therefore, it should be reinforce the need for the responsible teams for creating the best module on matters relating to parental adolescent communication and its content. The main content should be on how parents can create the feeling of comfort in communicating with their adolescents about sexual health topics. In addition, the important topics related to sexual and reproductive health must be included in the intervention module.

Lastly, parents who have a high level of knowledge about sexually transmitted infections, HIV and AIDS showed appropriate parenting skills in preventing adolescents' sexual health risk behavior. This proves that the importance of a high level of knowledge in adopting appropriate parenting skills. Therefore, awareness programs and the delivery of health information by relevant agencies such as the Ministry of Health and the Ministry of Women, Family and Community Development should be strengthened and expanded in conveying right information on sexual reproductive health prevention among the teens. The programs should be planned carefully, targeting the right group, choose an ef- 
fective approach for information delivery and ensure the presence of a warm welcome and requires a worthwhile expenditure.

\section{Acknowledgements}

The authors thank the UKMMC ethical committee for giving us approval and budget to conduct this study. We thank our respondents who sincerely participated in this study.

\section{Conflict of Interest}

All authors have declared no conflict of interest.

\section{References}

[1] Russell, S.T., Crockett, L.J. and Chao, R.K. (2010) Asian American Parenting and Parent-Adolescent Relationship. Springer Science + Business Media, New York. https://doi.org/10.1007/978-1-4419-5728-3

[2] Cripps, K. and Zyromski, B. (2009) Adolescents' Psychological Well-Being and Perceived Parental Involvement: Implications for Parental Involvement in Middle Schools. Research in Middle Level Education Online, 33, 1-13.

[3] Driscoll, A., Russell, S. and Crockett, L. (2008) Parenting Styles and Youth WellBeing across Immigrant Generations. Journal of Family Issues, 29, 185-209. https://doi.org/10.1177/0192513X07307843

[4] Goldenberg, H. and Goldenberg, I. (2008) Family Therapy an Overview. Cengage Learning, Brookscole.

[5] Nukunya, G.K. (2004) Tradition and Change in Ghana. An Introduction to Sociology. Ghana Universities Press, Accra.

[6] Olson, D. and De Frain, J. (2000) Marriage and Family: Diversity and Strengths. Mayfield Publishing Company, Mountain View.

[7] Prochaska, J.O. and Di Clemente, C.C. (1983) Stages and Processes of Self-Change of Smoking: Toward an Integrative Model of Change. Journal of Consulting and Clinical Psychology, 51, 390-395. https://doi.org/10.1037/0022-006X.51.3.390

[8] McConnaughy, E.A., Prochaska, J.O. and Velicer, W.F. (1983) Stages of Change in Psychotherapy: Measurement and Sample Profiles. Psychotherapy: Theory, Research \& Practice, 20, 368-375. https://doi.org/10.1037/h0090198

[9] Fleiss, J.L. (1981) Statistical Methods for Rates and Proportions. John Wiley \& Sons.

[10] Robinson, C., Mandleco, B., Olsen, S.F. and Hart, C.H. (1995) Authoritative, Authoritarian, and Permissive Parenting Practices: Development of a New Measure. Psychological Reports, 77, 819-830. https://doi.org/10.2466/pr0.1995.77.3.819

[11] Hutchinson, M.K. (2007) The Parent-Teen Sexual Risk Communication Scale (PTSRC-III): Instrument Development and Psychometrics. Nursing Research, 56, 1-8. https://doi.org/10.1097/00006199-200701000-00001

[12] Cleland, J. (2001) Illustrative Questionnaire for Interview-Surveys with Young People. World Health Organization.

[13] Department of Statistic (2015) Report of Household Income and Basic Amenities Survey 2014.

https://www.statistics.gov.my/index.php?r=column/pdfPrev\&id=aHhtTHVWNVYz TFBua2dSU1BRL1Rjdz09

[14] Pickhardt, C.E. (2012) Parenting Older Adolescents and the Generation Gap. 
https://www.psychologytoday.com/blog/survivingyourchildsadolescence/201210/pa renting-older-adolescents-and-the-generation-gap

[15] Prasad, R. (1992) Generation Gap, a Sociological Study of Inter Generational Conflicts. Mittal Publications, New Delhi.

[16] Arshat, Z. and Baharudin, R. (2011) The Relationship between Socioeconomic Factors and the Quality of Parenting Crowd Risky Behavior. Journal of Humanities, 17.

[17] Davis-Kean, P.E. (2005) The Influence of Parent Education and Family Income on Child Achievement: The Indirect Role of Parental Expectations and the Home Environment. Journal of Family Psychology, 19, 294-304. https://doi.org/10.1037/0893-3200.19.2.294

[18] Hill, N., Castellino, D.R., Lansford, J.E., et al. (2004) Parent Academic Involvement as Related to School Behavior, Achievement, and Aspirations: Demographic Variations across Adolescence. Child Development, 75, 1491-1509. https://doi.org/10.1111/j.1467-8624.2004.00753.x

[19] Guilamo-Ramos, V. and Bouris, A. (2008) Parent Adolescent Communication about Sex in Latino Families: A Guide for Practitioners. The National Campaign to Prevent Teen and Unplanned Pregnancy.

[20] Widman, L., Choukas-Bradley, S., Noar, S.M., Nesi, J. and Garrett, K. (2016) Parent-Adolescent Sexual Communication and Adolescent Safer Sex Behavior a Meta-Analysis. JAMA Pediatric, 170, 52-61. https://doi.org/10.1001/jamapediatrics.2015.2731

[21] Martino, S.C., Elliott, M.N., Corona, R., Kanouse, D.E. and Schuster, M.A. (2008) Beyond the "Big Talk": The Roles of Breadth and Repition in Parent Adolescent Communication about Sexual Topics. Pediatrics, 121, e612-e618. https://doi.org/10.1542/peds.2007-2156

[22] DiClemente, R.J., et al. (2001) Parental Monitoring: Association with Adolescents' Risk Behaviors. Pediatrics, 107, 1363-1368. https://doi.org/10.1542/peds.107.6.1363

[23] Sieverding, J.A., Adler, N., Witt, S. and Ellen, J. (2005) The Influence of Parental Monitoring on Adolescent Sexual Initiation. Archives of Pediatrics and Adolescent Medicine, 159, 724-729. https://doi.org/10.1001/archpedi.159.8.724

[24] Blum, R.W., et al. (2003) Adolescent Health in the Caribbean: Risk and Protective Factors. American Journal of Public Health, 93, 456-460. https://doi.org/10.2105/AJPH.93.3.456

[25] Ngom, P., Magadi, M.A. and Owuor, T. (2003) Parental Presence and Adolescent Reproductive Health among the Nairobi Urban Poor. Journal of Adolescent Health, 33, 369-377. https://doi.org/10.1016/S1054-139X(03)00213-1

[26] Burgess, V., Dziegielewski, F.S. and Green, E.C. (2005) Improving Comfort about Sex Communication between Parents and Their Adolescents: Practice-Based Research within a Teen Sexuality Group. The Journal of Brief Treatment and Crisis Intervention, 5, 379-390. https://doi.org/10.1093/brief-treatment/mhi023

[27] Burrus, B., Leeks, K.J., Sipe, T., et al. (2012) Person-Person Interventions Targeted to Parents and Other Caregivers to Improve Adolescent Health: A Community Guide Systematic Review. American Journal of Preventive Medicine, 42, 316-326. https://doi.org/10.1016/j.amepre.2011.12.001 
Submit or recommend next manuscript to SCIRP and we will provide best service for you:

Accepting pre-submission inquiries through Email, Facebook, LinkedIn, Twitter, etc. A wide selection of journals (inclusive of 9 subjects, more than 200 journals)

Providing 24-hour high-quality service

User-friendly online submission system

Fair and swift peer-review system

Efficient typesetting and proofreading procedure

Display of the result of downloads and visits, as well as the number of cited articles Maximum dissemination of your research work

Submit your manuscript at: http://papersubmission.scirp.org/

Or contact ojpm@scirp.org 